This is a postprint version of the following published document:

M. Fernández-Álvarez, F. Velasco, A. Bautista. Effect on wear resistance of nanoparticles addition to a powder polyester coating through ball milling, in: Journal of Coatings Technology and Research (online, May 2018), pp. 19

DOI: https://doi.org/10.1007/s11998-018-0106-z

(C) American Coatings Association 2018. 


\section{Effect on wear resistance of nanoparticles addition to a powder polyester coating through ball milling}

María Fernández-Álvarez, $1 \square$

Phone +34916248863

Emailmfalvare@ing.uc3m.es

Francisco Velasco, 1

Phone +34916249485

Emailfvelasco@ing.uc3m.es

Asunción Bautista, 1

Phone +34916249914

Email mbautist@ing.uc3m.es

1 Department of Materials Science and Engineering, IAAB, Universidad Carlos III de Madrid, Avda. Universidad 30, Leganés, Madrid, Spain

\section{Abstract}

The wear properties of a textured polyester powder coating with pyrogenic silica nanoparticles addition were evaluated. Raw powders of a commercial, textured polyester organic coating were mixed with low amounts of $\mathrm{SiO}_{2}$ nanoparticles (0.5-3 wt\%) using ball milling, a simple and economic method. Nanoparticles were mixed to the powder of thermoset organic coating for 10 min in a two-body planetary ball mill. Particle size distribution of powder was measured to evaluate the milling effect. The coatings were applied and cured in an industrial installation on aluminum substrates. Scanning electron microscopy (SEM) and atomic force microscopy (AFM) images of the coatings were taken to analyze the homogeneity of the organic coating. Roughness, gloss and color were measured in order to evaluate their appearance. The effect of nanoparticles on abrasive and erosion wear performances was measured. Pin-on-disk wear tests were carried out. Erosion measurements were performed with free fall of sand on the samples, a test based on ASTM D968 standard. The results showed that the milling process 
provides a good distribution of nanoparticles as no agglomerates were found. The addition of $0.5 \mathrm{wt} \%$ silica nanoparticles allows to improve the wear resistance of the coatings.

AQ1

\section{Keywords}

Polyester

Powder coating

Silica nanoparticles

Wear resistance

Ball milling

This paper was presented at the 13th Coatings Science International Conference (COSI) on June 26-30, 2017, in Noordwijk, The Netherlands.

\section{Introduction}

The use of organic powder coatings is increasingly widespread, and they have displaced conventional organic coatings in various industrial sectors as automobile, street furniture or household appliances. 1 The main reason relies on the great advantage of the absence of solvents and hazardous wastes, opposite to liquid organic coatings. 2 Cost is also reduced because powder materials can be recovered and they can be reused in the coating process. 3,4

In coatings and varnishes formed from liquid state, several investigations have been carried out in recent years on the use of nanoparticles. It has been proven the possibility of obtaining good results in some properties adding small amounts, providing that an adequate dispersion of the nanoparticles is achieved.2,5-8

The wear of organic coatings is among the most interesting features to improve the organic coating performance for different applications.2,9 The use of nanoparticles generally improves the wear resistance of coatings, being $\mathrm{SiO}_{2}$ one of the most used particulate nanoreinforcements. Most of the published studies are based on liquid organic coatings. This improvement has been shown in epoxy10 and polyurethane11 liquid resins.

AQ2

The dispersion of the nanoparticles in the polymer is, possibly, the most critical aspect. Regarding organic coatings or varnishes in liquid phase, previous studies show that the nanoparticles have been dispersed in the polymer using various 
methods such as predispersion in a solvent,12,13 magnetic stirring, 5 and mechanical methods. 14,15

Currently, there are still limited published studies about the addition of nanoparticles to powder organic coatings. The dispersion of the nanoparticles is also conditioned by the application method, since it is necessary that the powder is charged by corona effect to be applied. The published studies have resorted to methods of mixing commercial powder and nanoparticles by extrusion and to the remanufacture of the mixed powder.2,7,16-18 A study on the addition of nanocarbonates to epoxy powder organic coating 6 compares three possible mixing methods: (a) extrusion; (b) dissolving the resin in a solvent (acetone), followed by the remanufacturing of the powder; and (c) the preparation in situ nanocomposites. This last method was the one that promoted the best results, but it has the disadvantage that it can not be implemented using commercial powders.

Regarding the method of mixture chosen, there are hardly no references in the literature. Moradi et al.19 have already used the ball milling technique for powder organic coatings, obtaining a homogenous nanocomposite powder in an epoxy coating with high percentages of nanoparticles (SiAlON).

Other important features that depend on the presence of reinforcements are the charge of the powders in the electrostatic gun, the powder flow, and their viscosity when they melt. Moreover, the presence of nanoparticles can also affect the aesthetics of the coating, an important property in this series of applications. 4,20

The selection of a short milling time has the aim of keeping particle size distribution in certain limits not to affect the coating manufacturing process. It has to be taken into account that longer milling times (e.g., $5 \mathrm{~h}$ ) are chosen when the mixing process is carried out in liquid state, for instance to add pigments to liquid organic coating matrixes.21 Models regarding to liquid mixing by ball mill have also been recently developed 22 to describe the dispersion of pigment agglomerates in dispersion equipment (ball and three-roll mill), but they cannot be used on powder organic coatings.

Among the types of powder organic coatings, thermoset coatings possess great qualities in terms of good mechanical strength and excellent chemical and climatic resistance. 23 Nowadays, polyester-based organic coatings are the most used in applications as window profiles, garden furniture, garage doors or automotive parts.18,24 Polyester organic coatings have also good durability and resistance to ultraviolet radiation. 25 
Therefore, the aim of this work is to achieve a homogenous coating by adding different percentages of $\mathrm{SiO}_{2}$ nanoparticles, with a different and economic mixing method such as ball milling, improving the wear properties of the polyester coating.

\section{Experimental}

The selected powder organic coating was a textured white polyester (RAL 9010), provided by Cubson International Consulting S.L. (Spain). The selected silica nanoparticles were hydrophobic and pyrogenic, AEROSIL ${ }^{\circledR}$ fumed silica, model R202, with a specific surface area of $80-120 \mathrm{~m}^{2} / \mathrm{g}$ and an average size of $14 \mathrm{~nm}$. The polyester powder and nanoparticles were mixed in a planetary ball mill for $10 \mathrm{~min}$, with 8-mm-diameter steel balls, using a two-body planetary mill Pulverisette 5 (Fritsch, Idar-Oberstein, Germany). The volume of the grinding vessel was $250 \mathrm{ml}$. The ratio of the ball to powder mass was 10:1. Ten mills of $15 \mathrm{~g}$ were made for each mixture. All the process was carried out under dry conditions.

Mixes were prepared with different percentages by weight of nanoparticles: $0.5 \%, 1 \%, 2 \%$, and $3 \%$. In addition, the initial powder without nanoparticles was milled in the same conditions (labeled as $0 \%$ ) to evaluate the milling effect in the properties of the final coating.

Particle size distribution of powder mixes was measured with a laser analyzer Mastersizer 2000 (Malvern Instruments, Worcestershire, UK), for the asreceived (labeled as AR) organic coating powder and for the different milled powders. The distributions were measured under dry conditions, considering that the particles had an absorbance of 0.1 and a refractive index of 2.130, typical values of an opaque white pigment. Three measurements of each sample were performed.

The coating process was carried out at the facilities of Cubson International Consulting S.L. The application of the powder was implemented with an electrostatic spray gun Pulverizadora Manual Easyselect with a control unit OptiTronic (ITW GEMA, San Galo, Switzerland), using $100 \mathrm{kV}$ DC voltage source, on AA5005 aluminum sheets with dimensions of $142 \times 70 \mathrm{~mm}$.

Aluminum sheets were degreased with acetone before the coating process. The curing was performed in an oven at $180^{\circ} \mathrm{C}$ for $10 \mathrm{~min}$. The final thickness of the organic coatings was about $80-100 \mu \mathrm{m}$.

After curing, scanning electron microscopy (SEM) was used to characterize the coatings, using a Teneo SEM equipment (Thermo Fisher Scientific Inc., 
Waltham, USA) in order to study the morphology of the coatings and the influence of milling and nanoparticles on it. A $10 \mathrm{kV}$ electron beam was selected for imaging. Also, a semiquantitative analysis was performed by energydispersive spectroscopy (EDS). Atomic force microscopy (AFM) studies were performed using a MultiMode Nanoscope ${ }^{\circledR}$ IV (Digital Instruments, Veeco Metrology Group, Santa Barbara, CA, USA). The AFM measurements were carried out at room temperature, operating in the tapping mode, employing silicon tips with a force constant of about $40 \mathrm{~N} / \mathrm{m}$ and a resonance frequency close to $300 \mathrm{kHz}$, recording simultaneously height and phase images.

An Olympus DSX500 opto-digital microscope (Olympus Corporation, Tokyo, Japan) was used to obtain the roughness values of the organic coatings. The surface roughness values $(S a)$ were measured in three different zones of each sample.

The aesthetic properties were also evaluated. The gloss of the white organic coating was measured with a Refo 3 glossmeter (Hach Lange, Colorado, USA), using $60^{\circ}$ (to semigloss surfaces), in accordance to the ISO 2813 standard. Color measurements were carried out based on the ISO 11664 and measured under D65 illuminant, $10^{\circ}$ observer and exclusion of the specular component (SCE) on XRite ColorEye ${ }^{\circledR}$ XHT (X-Rite Inc., Michigan, USA). Five measurements were made on three different samples for each material with both techniques.

Abrasive and erosive wears were evaluated. Four tests in each sample, based on ASTM G 99 standard, were performed to evaluate abrasive wear with a pin-on disk (Microtest tribometer, TDP/10/SCM, Madrid, Spain). A flat pin ( $9 \mathrm{~mm}$ diameter) with a $\mathrm{SiC}$ abrasive paper (average $\mathrm{SiC}$ particle size, $125 \mu \mathrm{m}$ ) on it was used as countermaterial to test the organic coatings. Applied load $(10 \mathrm{~N})$, speed $(50 \mathrm{~mm} / \mathrm{s})$, and sliding distance $(100.5 \mathrm{~m})$ were fixed. Wear resistance was measured through mass loss. In order to carry out the erosive wear, a test based on ASTM D968 was developed. $20 \mathrm{~L}$ of silica coarse sand (1-2 mm diameter) was dropped from a height of $930 \mathrm{~mm}$ through a $19-\mathrm{mm}$-diameter duct on a specimen tilted $45^{\circ}$ above the horizontal. Three tests were performed on each of the materials, measuring the variation in thickness every $5 \mathrm{~L}$ of poured sand. After both wear tests (abrasive and erosion), worn surfaces were observed with SEM and opto-digital microscope, respectively, to study the wear mechanism.

\section{Results and discussion}

Although ball milling process carried out was designed to be a low-energy one, it affects particle size distribution. As it can be seen in Fig. 1, there is a slight reduction of particle sizes that could be related to the effect of both stainless 
steel balls and silica nanoparticles. Three of the most typical parameters used to describe a powder distribution (D10, D50 and D90) are shown in Fig. 2. As it can be clearly stated comparing the AR powder to the plain polyester milled powder $(0 \%)$, there is an important milling effect of particles due to stainless steel balls. Organic coating powder is much softer than steel (even the balls are not hardened); hence, collisions between balls and polyester particles provoke a reduction of particle size. As it can be seen, these collisions mainly affect larger particles, thus reducing D50 and particularly D90, while the size of the smaller particles (measured with D10) is only scarcely affected. This can be clearly understood taking into account that collisions between steel balls will trap more easily big than small particles. There are different models26,27 that simulate how particle size has influence on the specific breakage rate during the ball milling process, confirming those results. Moreover, a certain milling (particle size reduction) effect of nanoparticles cannot be discarded; when 1\% (by wt) or more silica is added, all parameters slightly decrease. The decrease in D10, particularly for $2 \%$ and $3 \%$ of silica, implies that finer particles are present in the distribution. The presence of agglomerates has not been found in the distributions (as shown in Fig. 1). The theoretical detection limit for the technique is $0.1 \mu \mathrm{m}(100 \mathrm{~nm})$, and no particles have been detected below $1 \mu \mathrm{m}$ in any of the distributions (as those shown in Fig. 1). Agglomerates, if they exist, should have a size bigger than $1 \mu \mathrm{m}$. SEM studies of powders have not detected them.

\section{Fig. 1}

Particle size distribution of as-received organic powder coating (green) and with $2 \% \mathrm{SiO}_{2}$ milled for $10 \mathrm{~min}$ (red)

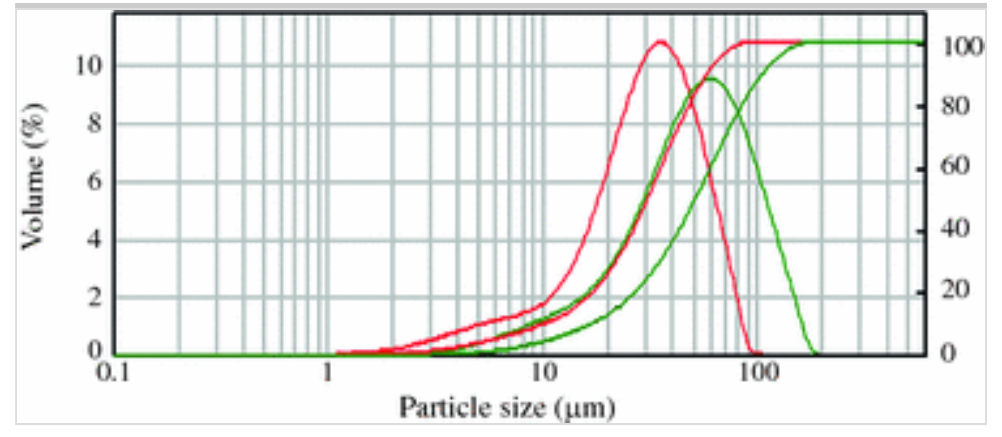

\section{Fig. 2}

D10, D50 and D90 parameters from particle size distribution of as-received organic powder coating and all milled organic powders 


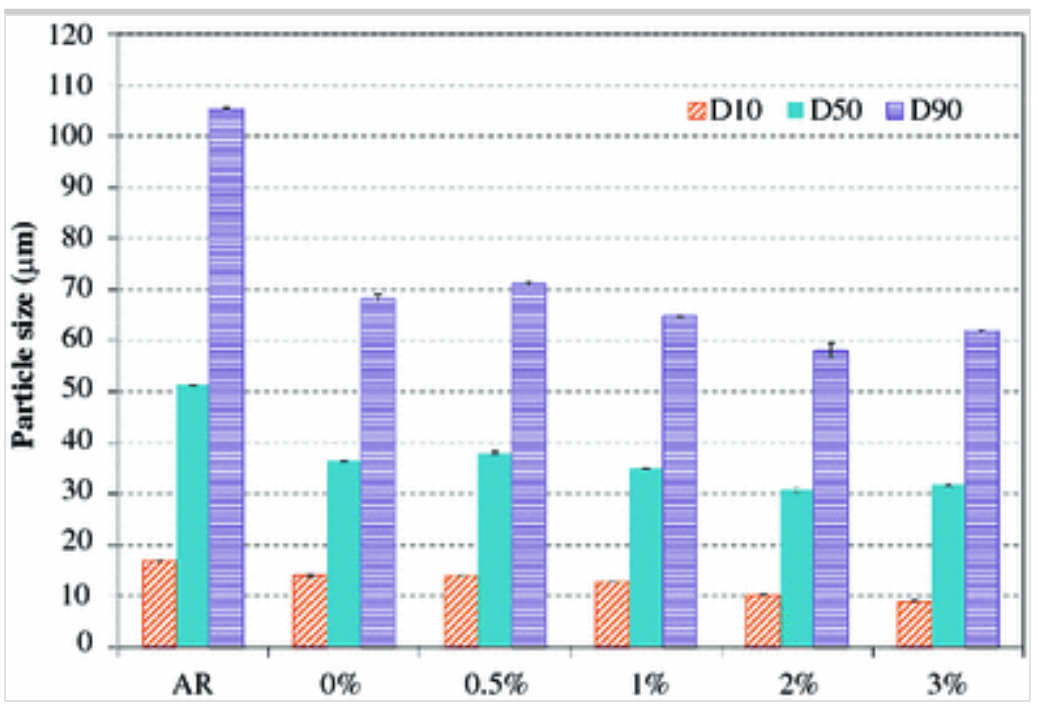

Fine particles could present difficulties in handling, and, in addition, an excess of fines increases not only the respiratory hazard but also the risk of explosion. The milling process taking place does not produce a strong presence of very fine particles that could promote these difficulties. Moreover, during the application it can be more difficult to accurately direct fine particles that should wrap around the items fully coating both sides.

The tested organic coating is a textured one. The surface roughness tends to decrease for milled particles (Fig. 3). This could be related to two effects. On the one hand, particle size distribution may affect surface roughness and, hence, the texturing effect of the used polyester. Finer particles promote smoother surfaces, as a more even curing process takes place. On the other, there could appear changes in the distribution of phases responsible for texturing due to interactions between nanoparticles and polymer. No clear influence about the addition of nanoparticles can be observed in the roughness of coatings manufactured from ball-milled powders.

Fig. 3

Surface roughness of organic coatings 


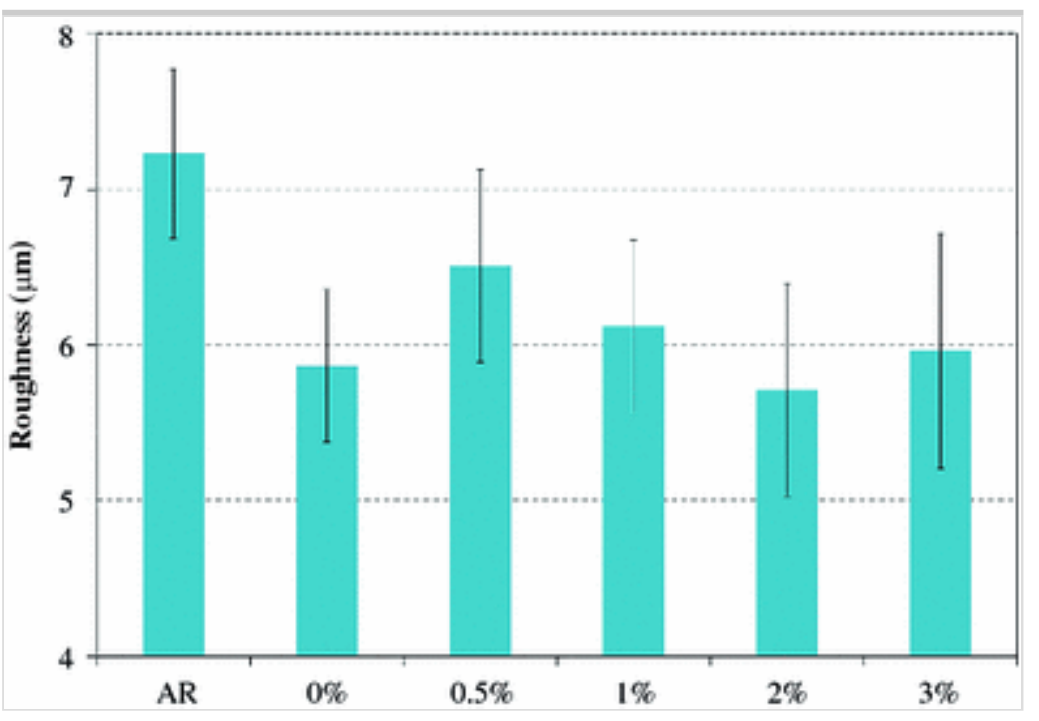

Moreover, the roughness modification caused by the ball milling of the powders may induce a transition in the surface aesthetics of the organic coating. Textured organic coatings have low gloss, as the texturing provokes light scattering, showing matt surface appearance. Theoretically, for nontextured organic coatings, a decrease in surface roughness will increase the gloss of the organic coating, as the reflection of the light is enhanced (being reflection less diffused) due to smoothening. This effect is found on plain organic coatings (without silica nanoparticles). In this case, the reduction of roughness caused by ball milling (Fig. 3) provokes an increase in gloss (Fig. 4).

Fig. 4

Gloss and color difference (related to as-received material) of organic coatings

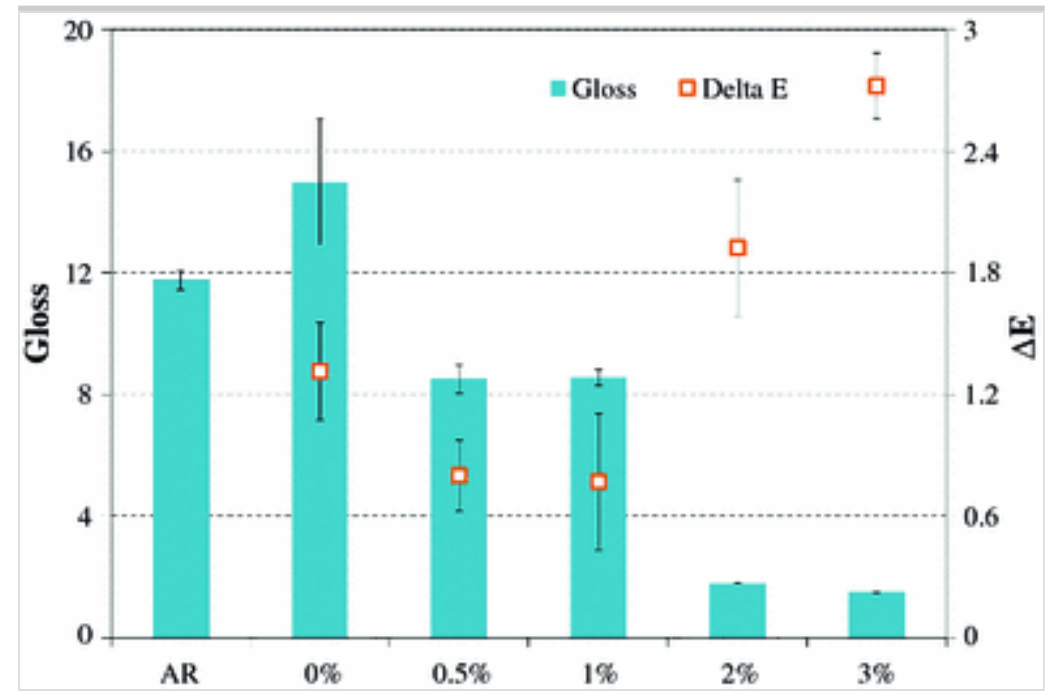

However, when silica nanoparticles are added, the gloss of the coating tends to decrease (Fig. 4). A similar effect of presence of nanoparticles on gloss has previously been found, although not quantified, in organic coatings 28 as well as 
in silane coatings containing silica nanoparticles.29 Aspects that may affect the reduction of gloss of silica containing organic coatings are uneven powder transport or uneven charging of particles.3,30 Although no particular problem about these issues was observed during the coating process, a possible influence can not be discarded. Moreover, other possible aesthetic defects that fine particles may promote related to a poor surface finish (like an orange peel effect30) have not been found in the coated surfaces.

The color parameters of the AR coating are $L^{*}=94.64, a^{*}=-0.84$ and $b^{*}=$ 5.56 , typical parameters of a white organic coating. Color deviations $(\Delta \mathrm{E})$ have been measured (Fig. 4), always referenced to the color of AR organic coating. The color parameter that mainly varies is always the $L^{*}$, which decreases when the percentage of nanoparticles increases, since there is a loss of luminosity. Ball milling seems to affect in the decrease of $L^{*}$, comparing $0 \%$ to the AR coating. The values of $a^{*}$ and $b^{*}$ are not meaningfully affected neither by the mixing process nor the nanoadditions. The nanoparticles do not affect dramatically the aesthetical properties of the coating. It seems that organic coatings containing higher amounts of silica promote bigger deviations (although it has to be pointed out that the differences seem to be acceptable). This change in color, together with the one of gloss, may indicate a small structural change in the organic coating. The measured values of $\Delta \mathrm{E}$ are not greater than 3 in any case. Pantoja et al.29 show similar values in silane coatings containing $1 \mathrm{wt} \%$ nanosilica. $\Delta \mathrm{E}$ values lower than 10 are considered acceptable, as it was assumed in previous works.31,32 Moreover, silica nanoparticles do not affect the hiding power of the organic coating, as no effect from the color of the aluminum substrate is noticeable.

SEM images of the coatings are shown in Fig. 5. Comparing Figs. 5a and 5b, it can be appreciated a dramatic refining of the structure. This refining affects the texture of the organic coating, being less rough (Fig. 3), and thus provoking an increase in gloss (Fig. 4). No particular change of structure is found when silica is added in amounts lower than 1\%; thus, the decrease in gloss should be related to the presence of nanoparticles. However, when higher amounts of nanoparticles are added, clear structural changes appear (Fig. 5c). The fact that nanoparticles affect softening and flowing processes during curing can be clearly appreciated, appearing voids. This voids act as light scattering points, hence strongly affecting gloss (Fig. 3).

\section{Fig. 5}

SEM analysis of organic coatings. (a) As-received, (b) milled raw organic coating $(0 \%),(\mathrm{c})$ milled organic coating with $2 \% \mathrm{SiO}_{2}$ 

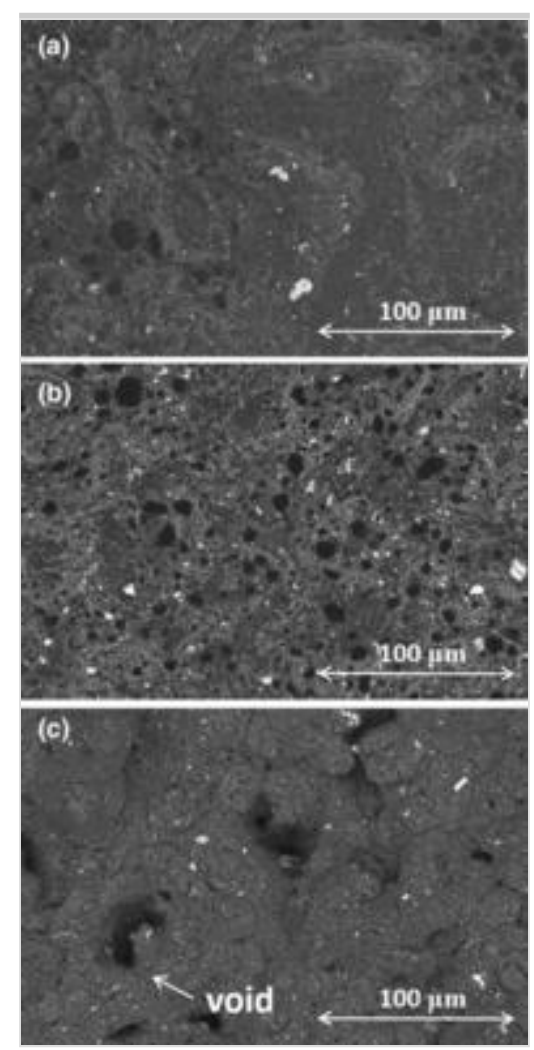

The detailed SEM study carried out with the coating has allowed to check that there are no agglomerates of nanoparticles that can be detected by this technique, even in the coatings with the highest amount of reinforcements studied. It cannot be discarded that the viscosity during curing stage helps to obtain a greater homogeneity. Figure 6 shows a detail of SEM analysis in sample containing 2\% silica nanoparticles. The bigger white areas correspond to $\mathrm{BaSO}_{4}$, while the smaller ones correspond to $\mathrm{TiO}_{2}$ and $\mathrm{SiO}_{2}$, usually found together in semiquantitative EDS analysis. $\mathrm{BaSO}_{4}$ and $\mathrm{TiO}_{2}$ are typical additives for powder organic coatings. Moreover, AFM (Fig. 7) does not provide any information about the possible existence of aggregates or agglomerates.

Fig. 6

SEM analysis of organic coatings. Detail of milled organic coating with $2 \% \mathrm{SiO}_{2}$

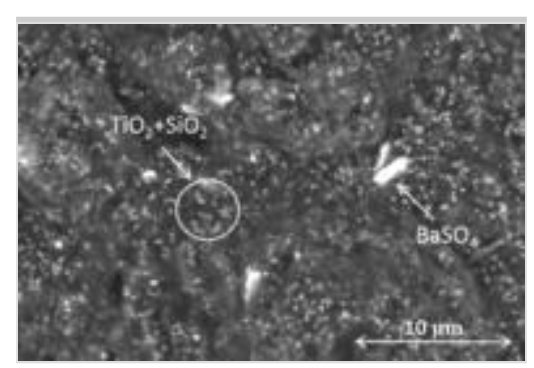

Fig. 7

AFM of organic coating with the milled organic coating with $2 \% \mathrm{SiO}_{2}$ 


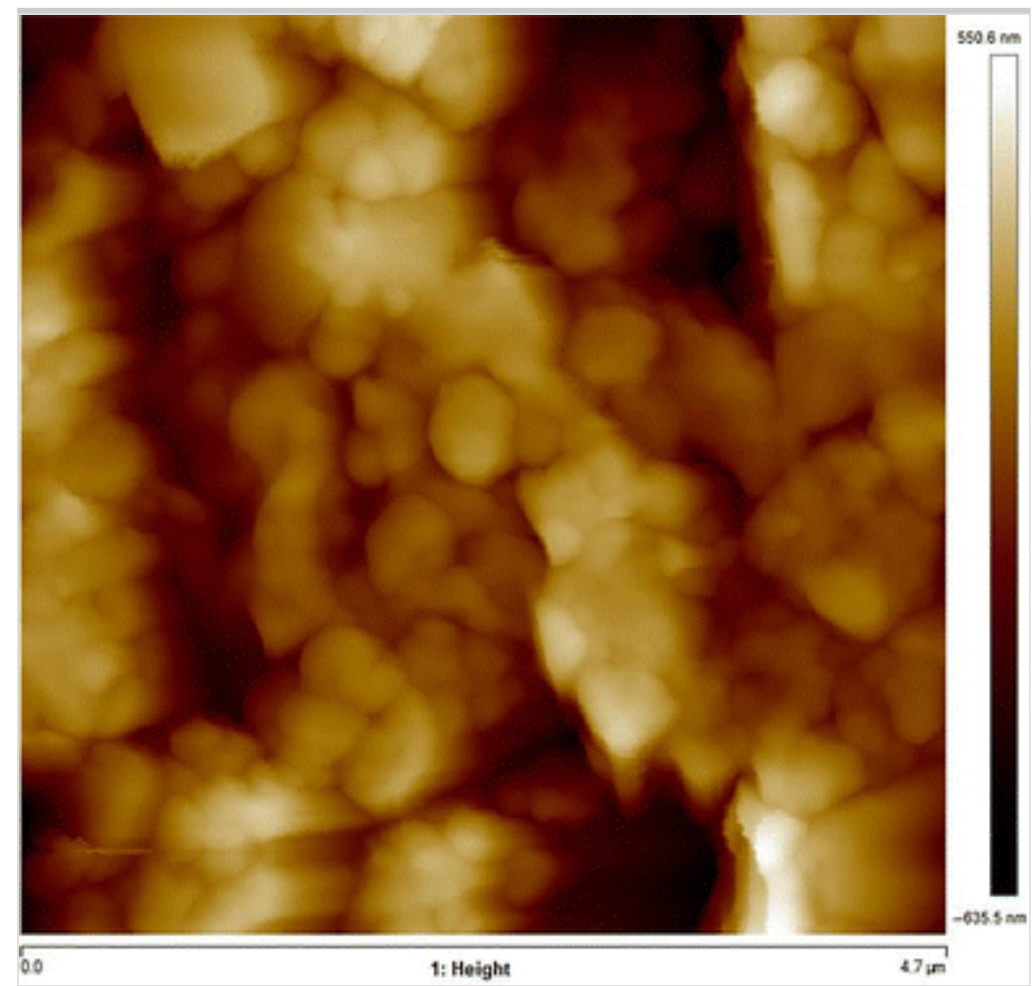

Structural and roughness changes seem to affect the abrasive behavior of the organic coatings. Figure 8 shows the mass loss of the different organic coatings after the pin-on-disk wear test. The positive effect of the decrease on roughness (Fig. 3) caused by ball milling can explain the reduced mass loss of this coating in absence of reinforcements. Moreover, ball milling can exert a certain positive effect on hardening the organic coating. A synergic effect between those effects and the introduction of nanoparticles in the structure of the organic coating explains the reduction of mass loss observed for organic coating with $0.5 \%$ silica when its results are compared to those of the AR coating. In addition, it can be noticed that the addition of nanoparticles causes a reduction of the mass loss compared to the $0 \%$ coating.

Fig. 8

Mass loss after abrasive wear test of organic coatings 


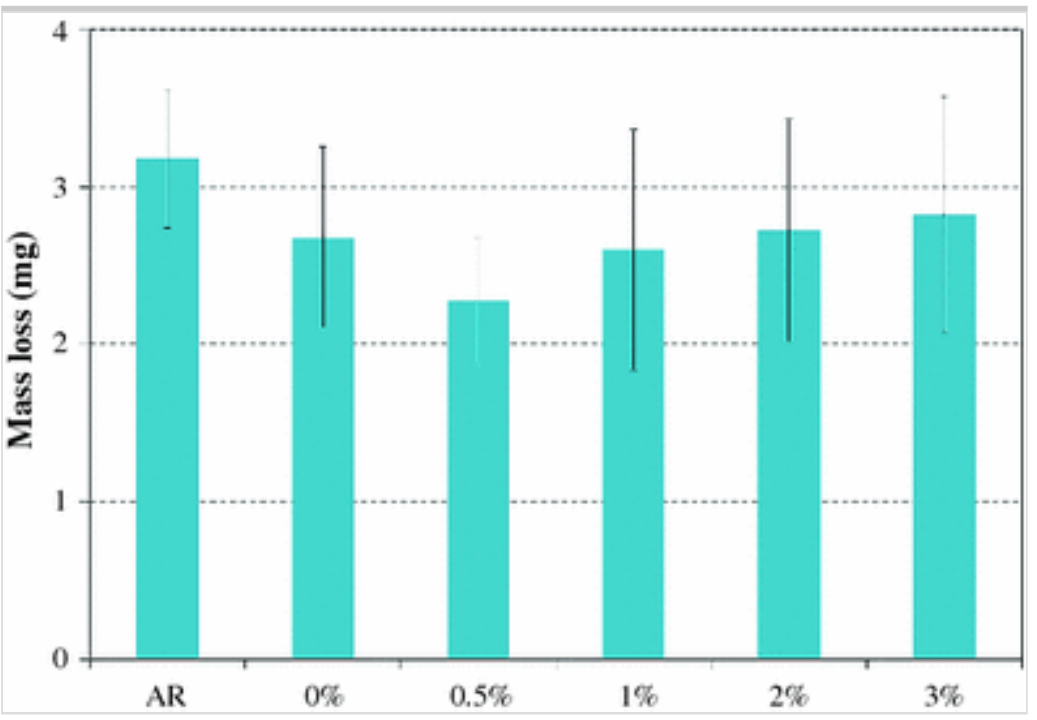

However, the structural changes taking place in the organic coating (Fig. 5c) change this tendency for higher silica contents. The voids that appear on the structure can affect the wear mechanism and explain the increase on the mass losses. There are studies showing that the voids in the coating provide a worse mechanical behavior.33 Although agglomerates have not been detected neither by SEM nor by AFM (Figs. 6 and 7), the presence of small aggregates cannot be discarded, particularly in highly loaded organic coatings, affecting the abrasive wear performance.

The SEM observations of the tracks caused by the pin-on-disk test inform that the wear mechanism is abrasive, as it would be expected. Figure 9a clearly shows the scratches in the $0 \%$ coating. Areas between the scratches appear where the structure of the organic coating can be seen. Some SiC particles were found in the worn track, coming from the abrasive paper used as countermaterial and giving notice of the good adherence of the organic coatings to the aluminum substrate.

Fig. 9

SEM images of wear mechanism of organic coatings. (a) Milled raw organic coating $(0 \%)$, (b) milled organic coating with $0.5 \% \mathrm{SiO}_{2}$
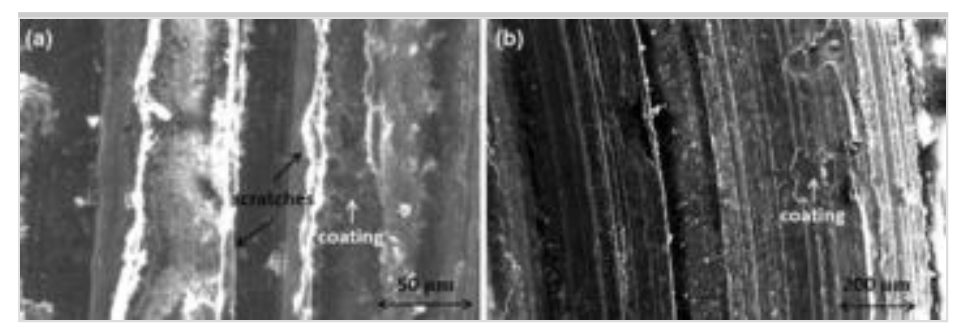
The addition of $0.5 \%$ silica does not change the abrasive nature of wear process, but there are more scratches (more homogeneously distributed in the track), but being less deep (Fig. 9b), thus explaining the lower mass loss. Original organic coating structure is found in an isolated manner and not between the scratches (as occurred in Fig. 9a). These results suggest that the silica nanoparticles have been adequately dispersed and placed in the structure of the polyester, promoting the hardening of the polymer by diverse mechanisms, as increasing the stiffness of the polymeric chains, 34 fostering the polymerization, 35 or contributing to absorption and distribution of the stresses in the material.36,37

When the amount of silica further increases, wear also increases, maybe due to the presence of voids, though the contribution of small aggregates to the mechanism cannot be completely discarded. Wear mechanism is still abrasive. The addition of silica nanoparticles sorts a positive effect when abrasive behavior is compared to the AR.

Figure 10 shows the results for erosive wear, while Fig. 11 shows images of the damages caused in the organic coatings that can inform about the mechanism. The milling process of the powders is negative for this property. Milling process has provoked a huge refinement of the structure of the cured organic coating (Figs. 5a and 5b). This may lead to a hardening effect, as abrasive wear results show (Fig. 8). But simultaneously, structure can become more brittle, and it has more difficulties to absorb impacts. When sand particles fall on the surface, a strong plowing effect must take place, and organic coating particles are removed. The addition of a small amount of nanoparticles is strongly positive. They will probably reduce crack propagation and hence organic coating detachment. Increasing the amount of nanoparticles promotes a less homogeneous structure, with the presence of voids, where a heterogeneous distribution of stresses can take place, thus affecting negatively particle detachment. Figure 11 shows the roughness of the surface after erosive wear, which is homogeneous for all cases. Figure 11a (for AR organic coating) and Fig. 11c (for $0.5 \%$ silica addition) shows a similar surface, being flat and smooth. However, Fig. 11b (for 0\% coating) and Fig. 11d (for 2\% silica addition) shows a deeper erosive wear. Therefore, the images would correspond with the results of Fig. 10, where it is observed that the highest losses of thickness coincide to $0 \%$ coating and the $2 \%$ silica addition. Silica nanoparticles addition then promotes a positive effect, as wear is reduced (when compared to $0 \%$ paint). This will remark that the addition of $0.5 \% \mathrm{SiO}_{2}$ improves the erosion resistance, comparing to the $0 \%$ organic coating.

\section{Fig. 10}

Thickness loss during erosion wear test of organic coatings for each $5 \mathrm{~L}$ of sand 


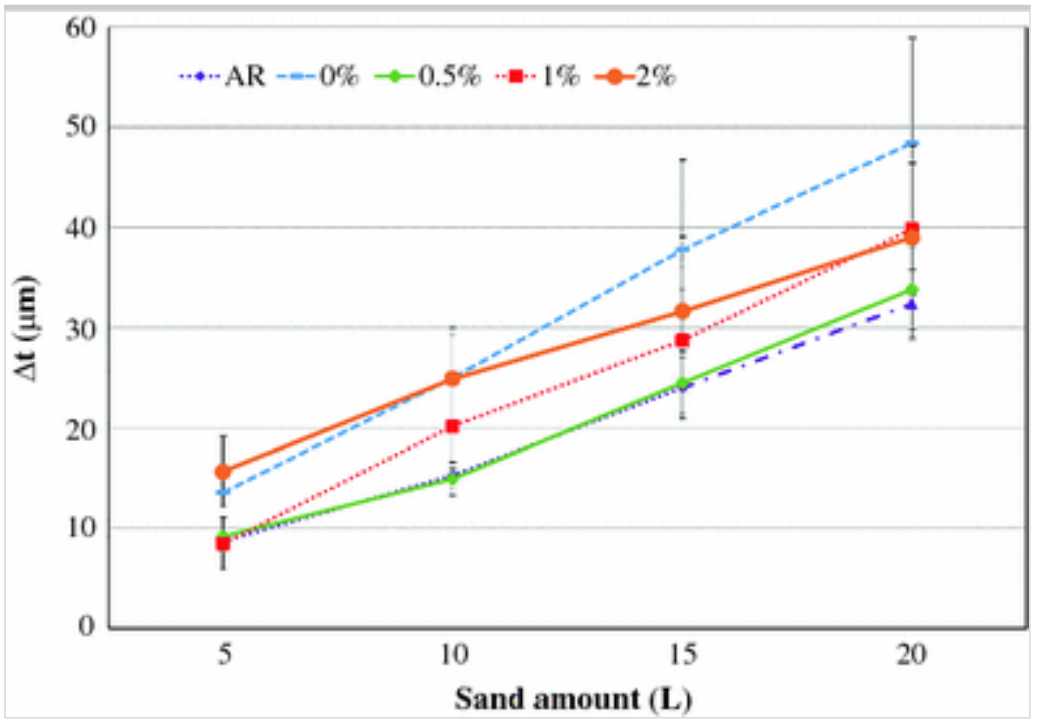

\section{Fig. 11}

Surface roughness of organic coatings. (a) As-received, (b) milled raw organic coating $(0 \%)$, (c) milled organic coating with $0.5 \% \mathrm{SiO}_{2}$, (d) milled organic coating with $2 \% \mathrm{SiO}_{2}$
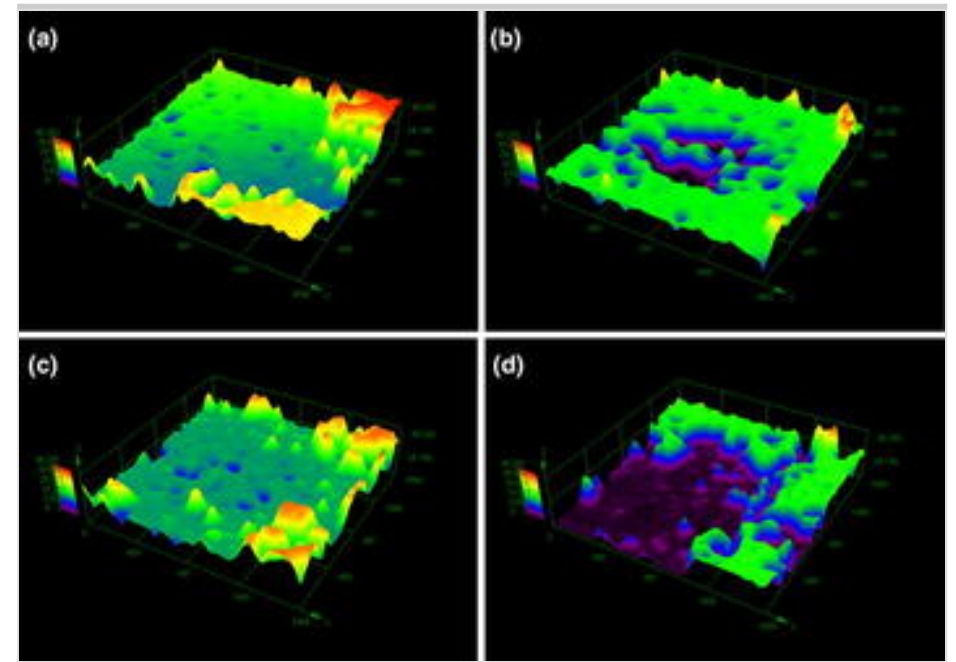

\section{Conclusions}

The main conclusions that can be drawn from this research are:

- Milling process can be an adequate process to mix low amounts of hydrophobic silica nanoparticles and polyester powder.

- The ball milling of the powders causes a decrease on the final roughness of the textured paint and a refinement of its structure.

- The addition of silica nanoparticles in amounts up to 3\% to the white 
polyester has not meaningfully affected the color of the paint.

- The addition of nanoparticles to the textured polyester has changed the morphological structure of the final coating, and voids tend to appear when amount of reinforcements higher than $1 \%$ is added.

- Additions of $0.5 \%$ silica nanoparticles to the selected powder polyester reduce the mass loss of the organic coating in the abrasive wear test.

- Ball milling does not improve erosion resistance, but the erosion resistance of the coating with $0.5 \% \mathrm{SiO}_{2}$ is similar to the as-received coating.

\section{Acknowledgments}

The authors acknowledge the financial support of Interreg SUDOE, through KrEaTive Habitat project (Ref. SOE1/P1/E0307), as well as Cubson International Consulting for their help with coating process.

\section{References}

1. Shi, Q, Huang, W, Zhang, Y, Zhang, Y, Xu, Y, Guo, G, "Curing of Polyester Powder Coating Modified with Rutile Nano-Sized Titanium Dioxide Studied by DSC and Real-Time FT-IR." J. Therm. Anal. Calorim., 108 (3) 1243-1249 (2012)

2. Mirabedini, SM, Kiamanesh, A, "The Effect of Micro and Nano-Sized Particles on Mechanical and Adhesion Properties of a Clear Polyester Powder Coating." Prog. Org. Coat., 76 (11) 1625-1632 (2013)

3. Huang, Q, Zhang, H, Zhu, J, "Flow Properties of Fine Powders in Powder Coating." Particuology, 8 (1) 19-27 (2010)

4. Barletta, M, Gisario, A, Trovalusci, F, Vesco, S, "Visual Appearance and Scratch Resistance of High Performance Thermoset and Thermoplastic Powder Coatings.” Prog. Org. Coat., 76 (1) 244-256 (2013)

5. Jarka, P, Tański, T, Matysiak, W, Krzemiński, Ł, Hajduk, B, Bilewicz, M, "Manufacturing and Investigation of Surface Morphology and Optical Properties of Composite Thin Films Reinforced by $\mathrm{TiO}_{2}, \mathrm{Bi}_{2} \mathrm{O}_{3}$ and $\mathrm{SiO}_{2}$ Nanoparticles." Appl. Surf. Sci., 424 206-212 (2017) 
6. Yu, H, Wang, L, Shi, Q, Jiang, S, Jiang, G, "Preparation of Epoxy Resin $/ \mathrm{CaCO}_{3}$ Nanocomposites and Performance of Resultant Powder Coatings." J. Appl. Polym. Sci., 101 (4) 2656-2660 (2006)

7. Kalaee, M, Akhlaghi, S, Nouri, A, Mazinani, S, Mortezaei, M, Afshari, M, Mostafanezhad, D, Dehaghi, HA, Amirsadri, A, Gohari, DP, "Effect of NanoSized Calcium Carbonate on Cure Kinetics and Properties of Polyester/Epoxy Blend Powder Coatings.” Prog. Org. Coat., 71 (2) 173-180 (2011)

8. Jawahar, P, Gnanamoorthy, R, Balasubramanian, M, "Tribological Behaviour of Clay-Thermoset Polyester Nanocomposites." Wear, 261 (7-8) $835-840$ (2006)

9. Sierros, KA, Kukureka, SN, "Tribological Investigation of Thin Polyester Substrates for Displays." Wear, 263 (7-12) 992-999 (2007)

10. Palraj, S, Selvaraj, M, Maruthan, K, Rajagopal, G, "Corrosion and Wear Resistance Behavior of Nano-Silica Epoxy Composite Coatings." Prog. Org. Coat., 81 132-139 (2015)

11. Zhou, S, Wu, L, Sun, J, Shen, W, "The Change of the Properties of Acrylic-Based Polyurethane Via Addition of Nano-Silica." Prog. Org. Coat., 45 (1) 33-42 (2002)

12. Sabzi, M, Mirabedini, SM, Zohuriaan-Mehr, J, Atai, M, "Surface Modification of $\mathrm{TiO}_{2}$ Nano-Particles with Silane Coupling Agent and Investigation of its Effect on the Properties of Polyurethane Composite Coating." Prog. Org. Coat., 65 (2) 222-228 (2009)

13. Maganty, S, Roma, MPC, Meschter, SJ, Starkey, D, Gomez, M, Edwards, DG, Ekin, A, Elsken, K, Cho, J, "Enhanced Mechanical Properties of Polyurethane Composite Coatings Through Nanosilica Addition." Prog. Org. Coat., 90 243-251 (2016)

14. Golgoon, A, Aliofkhazraei, M, Toorani, M, Moradi, MH, Rouhaghdam, AS, "Corrosion and Wear Properties of Nanoclay-Polyester Nanocomposite Coatings Fabricated by Electrostatic Method." Proc. Mater. Sci., 11 536-541 (2015)

15. Chen, C, Qiu, S, Cui, M, Qin, S, Yan, G, Zhao, H, Wang, L, Xue, Q, "Achieving High Performance Corrosion and Wear Resistant Epoxy Coatings 
Via Incorporation of Noncovalent Functionalized Graphene." Carbon, 114 356-366 (2017)

16. Piazza, D, Baldissera, AF, Kunst, SR, Rieder, ES, Scienza, LC, Ferreira, CA, Zattera, AJ, "Influence of the Addition of Montmorillonite in an Epoxy Powder Coating Applied on Carbon Steel.” Mater. Res., 18 (5) 897-903 (2015)

17. Sharifi, M, Ebrahimi, M, Jafarifard, S, "Preparation and Characterization of a High Performance Powder Coating Based on Epoxy/Clay Nanocomposite." Prog. Org. Coat., 106 69-76 (2017)

18. Piazza, D, Silveira, DS, Lorandi, NP, Birriel, EJ, Scienza, LC, Zattera, AJ, "Polyester-Based Powder Coatings with Montmorillonite Nanoparticles Applied on Carbon Steel.” Prog. Org. Coat., 73 (1) 42-46 (2012)

19. Moradi, MH, Aliofkhazraei, M, Toorani, M, Golgoon, A, Rouhaghdam, AS, "SiAlON-Epoxy Nanocomposite Coatings Corrosion and Wear Behavior." J. Appl. Polym. Sci., 133 (35) 1-13 (2016)

20. Zhou, S, Gu, G, "Study on the Morphology and Tribological Properties of Acrylic Based Polyurethane/Fumed Silica Composite Coatings." J. Mater. Sci., 39 (5) 1593-1600 (2004)

21. Hikku, GS, Jeyasubramanian, K, Vignesh Kumarb, S, "Nanoporous MgO as Self-Cleaning and Anti-Bacterial Pigment for Alkyd Based Coating." $J$. Ind. Eng. Chem., 52 168-178 (2017)

22. Kiil, S, "Mathematical Modeling of Pigment Dispersion Taking into Account the Full Agglomerate Particle Size Distribution." J. Coat. Technol. Res., 14 (1) 69-84 (2017)

23. Halász, L, Belina, K, "An Investigation into the Curing of Epoxy Powder Coating Systems.” J. Therm. Anal. Calorim., 119 (3) 1971-1980 (2015)

24. Belder, EG, Rutten, HJJ, Perera, DY, "Cure Characterization of Powder Coatings." Prog. Org. Coat., 42 (3-4) 142-149 (2001)

25. Gioia, C, Minesso, A, Cavalieri, R, Marchese, P, Celli, A, Colonna, M, "Powder Coatings for Indoor Applications from Renewable Resources and Recycled Polymers.” J. Coat. Technol. Res., 12 (3) 555-562 (2015) 
26. Carvalho, RM, de Tavares, LM, "Predicting the Effect of Operating and Design Variables on Breakage Rates Using the Mechanistic Ball Mill Model." Miner. Eng., 43 (1) 91-101 (2013)

27. Barrios, GKP, Carvalho, RM, de Tavares, LM, "Modeling Breakage of Monodispersed Particles in Unconfined Beds." Miner. Eng., 24 (3-4) 308318 (2011)

28. Valdesueiro, D, Hettinga, H, Drijfhout, JP, Lips, P, Meesters, GMH, Kreutzer, MT, van Ommen, JR, “Tuning Roughness and Gloss of Powder Coating Paint by Encapsulating the Coating Particles with Thin $\mathrm{Al}_{2} \mathrm{O}_{3}$ Films." Powder Technol., 318 401-410 (2017)

29. Pantoja, M, Abenojar, J, Martinez, MA, "Influence of the Type of Solvent on the Development of Superhydrophobicity from Silane-Based Solution Containing Nanoparticles.” Appl. Surf. Sci., 397 (1) 87-94 (2017)

30. Biris, AS, Mazumder, MK, Yurteri, CU, Sims, RA, Snodgrass, J, De, S, "Gloss and Texture Control of Powder Coated Films." Part. Sci. Technol., 19 (3) 199-217 (2001)

31. Gonnet, J, "Colour Effects of Co-Pigmentation of Anthocyanins Revisited-2. A Colorimetric Look at the Solucions of Cyanin Co-Pigmented by Rutin Using the CIELAB Scale.” Food Chem., 66 (3) 387-394 (1999)

32. Franceschi, E, Letardi, P, Luciano, G, "Colour Measurements on Patinas and Coatings System for Outdoor Bronze Monument." J. Cult. Herit., 7 (3) 166-170 (2006)

33. ST, D, Johansson, M, "Properties of Powder Coatings in Load Carrying Construction." J. Coat. Technol. Res., 2 (6) 473-481 (2005)

34. Xing, XS, Li, RKY, "Wear Behavior of Epoxy Matrix Composites Filled with Uniform Sized Sub-Micron Spherical Silica Particles." Wear, 256 (1-2) 21-26 (2004)

35. Malaki, M, Hashemzadeh, Y, Karevan, M, "Effect of Nano-Silica on the Mechanical Properties of Acrylic Polyurethane Coatings." Prog. Org. Coat., $101477-485$ (2016)

36. Zhou, SX, Wu, LM, Sun, J, Shen, WD, "Effect of Nanosilica on the Properties of Polyester-Based Polyurethane." J. Appl. Polym. Sci., 88 (1) 
$189-193(2003)$

37. Domun, N, Hadavinia, H, Zhang, T, Sainsbury, T, Liaghat, GH, Vahid, S, "Improving the Fracture Toughness and the Strength of Epoxy Using Nanomaterials-A Review of the Current Status." Nanoscale, 7 (23) 1029410329 (2015) 